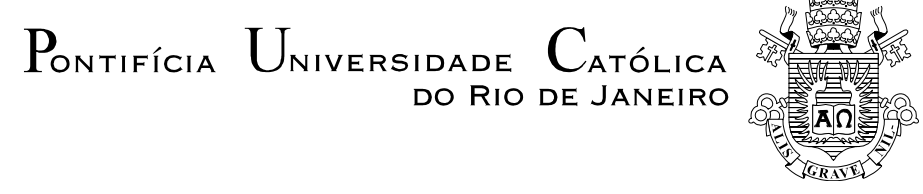

Renata Ester Heinemann

\title{
Sustentabilidade Fiscal Frente a Choques de Política Monetária: Encontrando a Trajetória Ótima de Acumulação de Dívida
}

Dissertação de Mestrado

Dissertação apresentada como requisito parcial para obtenção do título de Mestre pelo Programa de PósGraduação em Economia da PUC-Rio.

Orientadores: Eduardo Henrique de Mello Motta Loyo Juan Pablo Torres-Martinez 


$$
\text { Pontifícia Universidade C Católica }
$$

Renata Ester Heinemann

\section{Sustentabilidade Fiscal Frente a Choques de Política Monetária: Encontrando a Trajetória Ótima de Acumulação de Dívida}

Dissertação apresentada como requisito parcial para obtenção do título de Mestre pelo Programa de PósGraduação em Economia da PUC-Rio. Aprovada pela Comissão Examinadora abaixo assinada.

Eduardo Henrique de Mello Motta Loyo
Orientador
Departamento de Economia PUC-Rio

Juan Pablo Torres-Martinez

Co-orientador

Departamento de Economia PUC-Rio

Ilan Goldfajn

Departamento de Economia PUC-Rio

João Pontes Nogueira

Coordenador(a) Setorial do Centro de Ciências Sociais - PUC-Rio 
Todos os direitos reservados. É proibida a reprodução total ou parcial do trabalho sem autorização da universidade, da autora e do orientador.

\section{Renata Ester Heinemann}

Graduou-se em Engenharia de Produção pela Escola Politécnica da Universidade de São Paulo. No Programa de Mestrado em Teoria Econômica, concentrou sua pesquisa em Macroeconomia, com ênfase em Economia Monetária. Atuou como monitora e foi eleita para participar do programa "Bolsa Aluno Nota 10", patrocinado pela Faperj.

Ficha Catalográfica

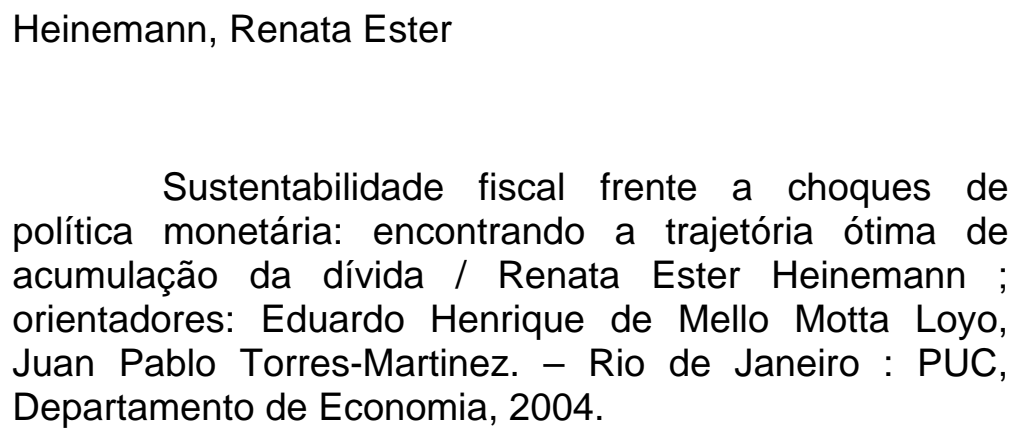

Sustentabilidade fiscal frente a choques de política monetária: encontrando a trajetória ótima de acumulação da dívida / Renata Ester Heinemann ; orientadores: Eduardo Henrique de Mello Motta Loyo, Juan Pablo Torres-Martinez. - Rio de Janeiro : PUC, Departamento de Economia, 2004.

85 f. : il. ; $30 \mathrm{~cm}$

Dissertação (mestrado) - Pontifícia Universidade Católica do Rio de Janeiro, Departamento de Economia.

Incluí referências bibliográficas.

1. Economia - Teses. 2. Sustentabilidade fiscal. 3. Taxação ótima. 4. Método de Bellman. I. Loyo, Eduardo Henrique de Mello Motta. II. Torres-Martinez, Juan Pablo. III. Pontifícia Universidade Católica do Rio de Janeiro. Departamento de Economia. III. Título. 
Aos meus pais, Julio e Bela, e ao meu irmão Felipe. 


\section{Agradecimentos}

Aos professores do Departamento de Economia da Pontifícia Universidade Católica do Rio de Janeiro, por dedicarem-se em oferecer um curso reconhecido pela excelência, que imprime uma permanente marca de destaque nos alunos de mestrado em Teoria Econômica. Este esforço é parte da constante motivação que tive durante a redação deste trabalho.

Aos meus orientadores Loyo e Juan Pablo, pela atenção, sugestões e desafios propostos ao longo da execução desta tese. Agradeço, também, pelo aprendizado fornecido durante os excelentes cursos ministrados, que assim como os debates que muito contribuiram para meu desenvolvimento, carregarei para sempre. Em especial, gostaria de deixar registrado minha gratitude ao Juan Pablo, que durante os anos de convivência se tornou um grande amigo.

Ao professor Ilan Goldfajn, pela participação na banca e pelo convívio durante a monitoria de Macro I, que tanto colaborou para redobrar minha motivação durante o mestrado.

Aos professores Ricardo Paes de Barros, Walter Novaes e Gustavo Gonzaga, que participaram ativamente da minha formação durante o mestrado.

Não posso deixar de mencionar o amigo Nilson Teixeira, absolutamente determinante no prosseguimento de meus estudos, pelos aconselhamentos sempre escutados com carinho e tão importantes na minha formação. 
A minha amiga de longa data Pati Davanzzo, que, apesar da distância de uns 450 quilómetros, foi tão importante para mim durante meu período de moradia no Rio que sinto como se estivesse dividindo a casa comigo. Registro aqui meu carinho e gratidão a esta grande amiga.

À quem devo pela essência do que sou, meu companheiro e maior amigo Márcio, que faz de todos os momentos da vida momentos especiais, e que mais do que em qualquer outra época esteve sempre comigo durante o mestrado. Obrigado por todo apoio e toda felicidade que compartilho ao seu lado.

Finalmente, ao Governo Brasileiro pelo importante apoio financeiro concedido através da Coordenação de Aperfeiçoamento de Pessoal de Nível Superior (Capes), e ao Governo do Estado do Rio de Janeiro, pelo honroso auxílio concedido via Fundação de Amparo à Pesquisa do Estado do Rio de Janeiro (Faperj). 


\section{Resumo}

Heinemann, Renata Ester. Sustentabilidade Fiscal Frente a Choques de Política Monetária: Encontrando a Trajetória Ótima de Acumulação de Dívida. Rio de Janeiro, 2004. 85p. Dissertação de Mestrado - Departamento de Economia, Pontifícia Universidade Católica do Rio de Janeiro.

O trabalho consiste no desenvolvimento de um modelo para explicar a razão pela qual em algumas economias, especialmente a brasileira, se constata que, diante de choques à taxa de juros real, não se observa suavização da taxação, mas sim variações das alíquotas de impostos seguindo variações do ciclo econômico. Mostra-se assim formalmente a ligação entre a sustentabilidade fiscal e variações na carga tributária mais fortemente evidenciada em países em que houve a necessidade de passar por planos de ajustes fiscais - situação esta que pode sugerir a suscetibilidade à ocorrência de crise de confiança em relação ao cumprimento das obrigações de pagamento da dívida soberana, ou seja, probabilidade positiva de repúdio da dívida. A partir do modelo, é possível concluir que uma trajetória não fixa para a taxação pode se estabelecer como resultado ótimo diante de imperfeições no processo de estabilização fiscal. É um modelo que permite endogeneizar e escolher de forma ótima o superávit primário a cada período de tempo.

\section{Palavras-chave}

Sustentabilidade Fiscal, Taxação Ótima, Método de Bellman 


\section{Abstract}

Heinemann, Renata Ester. Fiscal Sustainability Under Monetary Policy Shocks: Obtaining the Optimal Debt Accumulation Path Rio de Janeiro, 2004. 85p. MSc Dissertation - Departamento de Economia, Pontifícia Universidade Católica do Rio de Janeiro.

This paper develops a model to explain why in some economies, and especially in the Brazilian economy, we see evidence that taxation is not smoothened when facing real interest rate shocks. Instead, tax rates vary following the economic cycle. We show through a formal model the connection between fiscal sustainability and the variation of the level of taxation, a pattern more often observed in countries that went through fiscal adjustment plans - a situation that might suggest the possibility of occurrence of confidence crisis regarding the payment of sovereign debt, or a positive probability of debt default. From the model, it is possible to conclude that a non-constant taxation path can be established as an optimal result in such economies. It is a model that allows choosing endogenously and optimally the necessary fiscal superavit in each period of time.

\section{Keywords}

Fiscal Sustainability, Optimal Taxation, Bellman Method. 


\section{Sumário}

1 Introdução 15

1.1. Motivação 15

1.2. Objetivo 21

2 O Modelo 23

2.1. Descrição 23

2.2. Modelagem Proposta $\quad 27$

2.3. O Método de Bellman 33

2.4. Resolução do Modelo 37

3 Resultados $\quad 39$

3.1. Observeções Iniciais 39

3.2. Resultados Obtidos 44

3.3. Sensibilidade do Modelo em Relação aos Parâmetros 49

3.4. Modificando a Distribuição da Variável Estocástica 58

3.5. Modificando o Limite de Sustentabilidade da Dívida 62

3.6. Considerações Finais 72

3.7. O Caso da Economia Brasileira 72

4 Conclusão $\quad 75$

5 Referências Bibliográficas $\quad 79$

6 Apêndice $\quad 81$ 


\section{Lista de Figuras}

Figura 1 - Dados Brasileiros: Dívida Total e Carga Tributária 20

Figura 2 - Diagrama: O Limite de Sustentabilidade da Dívida 26

Figura 3 - Gráfico G1 - Solução (1) 45

Figura 4 - Gráfico G2 - Solução (2) 45

Figura 5 - Gráfico G3 - Solução (3) 45

Figura 6 - Gráfico G4 - Solução (4) 45

Figura 7 - Gráfico G5 - Solução (5) 45

Figura 8 - Gráfico G6 - $\beta=0,5$ (1) 51

Figura 9 - Gráfico G7 - $\beta=0,5(2)$

Figura 10 - Gráfico G8 - $\beta=0,5$ (3) 51

Figura 11 - Gráfico G9 - $\beta=0,5(4)$

Figura 12 - Gráfico G10 - $\beta=0,5(5)$

Figura 13 - Gráfico G11 - $\beta=0,99$ (1) 52

Figura 14 - Gráfico G12 - $\beta=0,99$ (2) 52

Figura 15 - Gráfico G13 - $\beta=0,99$ (3) 52

Figura 16 - Gráfico G14 - $\beta=0,99$ (4) 52

Figura 17 - Gráfico G15 - $\beta=0,99$ (5) 52

Figura 18 - Gráfico G16 - k=0,001 (1) 54

Figura 19 - Gráfico G17 - k=0,001 (2) 54

Figura 20 - Gráfico G18 - k=0,001 (3) 54

Figura 21 - Gráfico G19-k=0,001 (4) 54

Figura 22 - Gráfico G20 - k=0,001 (5) 54

Figura 23 - Gráfico G21 - k=0,01 (1) 55

Figura 24 - Gráfico G22 - k= 0,01 (2) 55

Figura 25 - Gráfico G23 - k=0,01 (3) 55

Figura 26 - Gráfico G24 - k= 0,01 (4) 55

Figura 27 - Gráfico G25 - k= 0,01 (5) 55

Figura 28 - Gráfico G26 - k=0,5 (1) 56 
Figura 29 - Gráfico G27 - k = 0,5 (2)

Figura 30 - Gráfico G28 - k = 0,5 (3)

Figura 31 - Gráfico G29 - k = 0,5 (4) 56

Figura 32 - Gráfico G30 - k = 0,5 (5) 56

Figura 33 - Gráfico G31 - k= 0,9 (1) 57

Figura 34 - Gráfico G32 - k = 0,9 (2) 57

Figura 35 - Gráfico G33 - k= 0,9 (3) 57

Figura 36 - Gráfico G34 - k= 0,9 (4) 57

Figura 37 - Gráfico G35 - k= 0,9 (5) 57

Figura 38 - Gráfico G36 - $\omega_{\mathrm{t}} \sim \mathrm{N}(0 ; 1)(1)$

Figura 39 - Gráfico G37 - $\omega_{\mathrm{t}} \sim \mathrm{N}(0 ; 1)(2)$

Figura 40 - Gráfico G38 - $\omega_{\mathrm{t}} \sim \mathrm{N}(0 ; 1)(3)$

Figura 41 - Gráfico G39 - $\omega_{t} \sim N(0 ; 1)(4)$

Figura 42 - Gráfico G40 - $\omega_{t} \sim \mathrm{N}(0 ; 1)(5)$

Figura 43 - Gráfico G41 - $\omega_{t} \sim \mathrm{N}(0 ; 10)(1)$

Figura 44 - Gráfico G42 - $\omega_{t} \sim \mathrm{N}(0 ; 10)(2)$

Figura 45 - Gráfico G43 - $\omega_{t} \sim N(0 ; 10)(3)$

Figura 46 - Gráfico G44 - $\omega_{t} \sim N(0 ; 10)(4)$

Figura 47 - Gráfico G45 - $\omega_{t} \sim \mathrm{N}(0 ; 10)(5)$

Figura 48 - Gráfico G46 - $x_{0}=5$ (3) 65

Figura 49 - Gráfico G47 - $x_{0}=5$ (4) 65

Figura 50 - Gráfico G48 - $x_{0}=5$ (5) 65

Figura 51 - Gráfico G49- $x_{0}=15$ (3) 66

Figura 52 - Gráfico G50 - $x_{0}=15$ (4) 66

Figura 53 - Gráfico G51 - $x_{0}=15(5)$

Figura 54 - Gráfico G52 - $x_{0}=20$ (3) 67

Figura 55 - Gráfico G53 - $x_{0}=20$ (4) 67

Figura 56 - Gráfico G54 - $x_{0}=20$ (5) 67

Figura 57 - Gráfico G55 - $x_{0}=25$ (3) 68 
Figura 58 - Gráfico G56 - x $=25$ (4) 68

Figura 59 - Gráfico G57 - $x_{0}=25(5) \quad 68$

Figura 60 - Gráfico G58 - $x_{0}=85(3) \quad 70$

Figura 61 - Gráfico G59 - $x_{0}=85$ (4) 70

Figura 62 - Gráfico G60 - x = 85 (5) 70 


\section{Lista de Tabelas}

Tabela 1 - Dados Fiscais e de PIB Brasileiros 43

Tabela 2 - Modificações no Limite de Sustentabilidade 63

Tabela 3 - Resultados para Diferentes Limites de Sustentabilidade $\quad 73$ 